\title{
CONTACT ANGLE OF COAL WETTING WITH WATER
}

(C) V.M. Kuznichenko, PhD in technical sciences, A.V. Sytnik, PhD in technical sciences (State Enterprise "Ukrainian State Research Coal Chemical Institute (UKHIN)", 61023, Kharkov, Vesnina st., 7, Ukraine)

It is known that in the process of coking a compacted coal charge during its ramming in an industrial ramming-loading-pushing machine, the moisture of the charge plays the role of a compaction agent. On the basis of this, the authors put forward a reasonable assumption that the higher the ability of coal grains to hydration, the stronger the contact between them and, accordingly, the greater the density of the formed rammed coal cake. Therefore, the determination of the ability to hydrate the surface of coal used in the charge for ramming is of both theoretical and practical importance. For the numerical determination of this indicator, the authors have chosen the contact angle of wetting, determined by the method of "sessile drop" of water on a carbon substrate. The article presents the results of a study of the ability of various brands of coal to hydrate. The article describes the characteristics of the studied grades of coal and their contact angle of wetting with water $(\theta)$ after 1,2 and 3 minutes of keeping the drop on a polished surface. Since according to the literature data, the organic mass of coal is hydrophobic, and mineral impurities, as a rule, are hydrophilic, the authors investigated the degree of influence of the "ash content of coal" $\left(A^{d}\right)$ indicator on the value of $\theta$. To determine the influence of the wetting angle and the internal moisture content of coal after 14 hours of moisture saturation in water $\left(W_{\text {ins }}\right)$ on the strength $\left(\sigma_{s s}\right)$ of the rammed sample, the corresponding graphical dependence was determined.

The data obtained indicate that any significant relationship between $A^{d}$ and $\Theta$ is absent, the correlation coefficient is insignificant $(r=0.28)$. Thus, the predominant factor in the hydration of cleaned coal is the properties of its organic matter. The correlation between $\theta$ and the yield of volatile substances $V^{d a f}$ and the content of vitrinite $V_{t}$ is also insignificant - the correlation coefficient is up to 0,43 and 0,50 respectively. A close relationship of the contact angle was found with the reflection coefficient of vitrinite $R_{o}$ $(r=0.72)$, the internal moisture content of coal after 14 hours of saturation in water, $W_{\text {ins }}(r=0,65)$, and the shear strength of the rammed coal sample $\sigma_{s s}(r=0,68)$.

Keywords: coal, ability to hydration, contact angle of wetting, organic mass of coal, mineral impurities, density, strength.

Corresponding author V.M. Kuznichenko,e-mail: : ko@ukhin.org.ua 